\title{
Motivos que levaram as gestantes a não se vacinarem contra H1N1
}

\author{
Reasons why pregnant women did not vaccinate \\ against Influenza A H1N1
}

Bárbara Fernanda Barroso Pereira ${ }^{1}$ Magda Aparecida Santos Martins ${ }^{1}$ Thiago Luis de Andrade Barbosa ${ }^{2}$ Carla Silvana Oliveira e Silva ${ }^{2}$ Ludmila Mourão Xavier Gomes ${ }^{3}$

\footnotetext{
${ }^{1}$ Enfermagem, Faculdades Santo Agostinho de Montes Claros. Av. Osmane Barbosa 1610, Planalto. 39404-006 Montes Claros MG. barbynanda04@yahoo.com.br ${ }^{2}$ Departamento de Assistência em Enfermagem, Centro de Ciências Biológicas e da Saúde, Universidade Estadual de Montes Claros. ${ }^{3}$ Ciências da Saúde, Universidade Federal de Minas Gerais.
}

\begin{abstract}
Pregnant women constitute a risk group for any infection due to their low immunity condition. This is a descriptive study with a qualitative approach, grounded in the Theory of Social Representations that sought to understand the reasons why pregnant women did not vaccinate against influenza $A$ (H1N1). The study included 10 women who were pregnant during the vaccination campaign of 2010. Data were collected in May 2011 through interviews and interpreted by content analysis. From the speeches it was possible to identify the various representations that the vaccine against H1N1 had for these women during their pregnancy as an element which would cause miscarriage and birth defects. The reasons why pregnant women did not vaccinate against H1N1 are associated with fear, lack of information and the myths and beliefs that people bring in their representations and their cultural values.
\end{abstract} Key words Pregnant women, Vaccination, Influenza A subtype virus H1N1, Health education
Resumo As grávidas constituem um grupo de risco para qualquer infecção devido à baixa imunidade que apresentam. Estudo descritivo com abordagem qualitativa, ancorada na Teoria das Representações Sociais que objetivou compreender os motivos que levaram as gestantes a não se vacinarem contra a Influenza A (H1N1). Participaram do estudo 10 mulheres que estavam grávidas no período da campanha de vacinação de 2010. Os dados foram coletados em maio de 2011 mediante entrevistas semiestruturadas e discutidas pela análise de conteúdo. A partir dos discursos foi possivel identificar as várias representações que a vacina H1N1 tinha para essas mulheres no período de sua gestação, como elemento que causaria aborto e má formação do feto. Os motivos que levaram as gestantes a não se vacinarem contra a gripe H1N1 estão associados ao medo, à falta de informação e aos mitos e crenças que a população traz nas suas representações e nos seus valores culturais.

Palavras-chave Gestantes, Vacinação, Vírus da Influenza A Subtipo H1N1, Educação em Saúde 


\section{Introdução}

O vírus da Influenza A (H1N1) surgiu entre março e abril de 2009 no México e nos Estados Unidos e se disseminou rapidamente no Hemisfério Norte e Europa. Em junho, a Organização Mundial de Saúde (OMS) elevou a epidemia para o nível máximo de alerta (nível 6), oficialmente declarando que o mundo estava em uma pandemia da nova gripe. Em todo o mundo, pessoas se infectaram com a nova doença e suas consequências apareciam muito rapidamente, sem que fosse possível fazer algo para conter tal situação ${ }^{1}$.

Em 2009, a OMS registrou cerca de 280 casos no Canadá e 1.626 nos Estados Unidos. No total, foram confirmadas no mundo 8.768 mortes. O Ministério da Saúde do Brasil (MS) recebeu testes para a confirmação diagnóstica de Influenza A (H1N1) de origem suína, em maio de 2009, o que permitiu que fossem confirmados em todo o território nacional oito casos da nova doença ${ }^{1}$.

Em todo o mundo, foram produzidas vacinas no sentido de controlar a pandemia. No Brasil, o Instituto Butantã, ligado à Secretaria de Saúde de São Paulo, foi o responsável por desenvolver as vacinas contra a Influenza (gripe comum) e esteve à frente também do desenvolvimento da imunização contra a Influenza A (H1N1). O público-alvo adotado pelo MS para receber a vacina foi definido pela OMS. No princípio de 2010, o MS estabeleceu um calendário vacinal e os grupos designados a receberem a vacina: profissionais de saúde, que, de forma direta, estavam em contato com a doença; indivíduos com doenças crônicas e gestantes; jovens entre 20 e 39 anos e, por fim, crianças ou idosos com enfermidades crônicas ${ }^{2}$.

No que diz respeito às gestantes, destaca-se que, durante a gravidez, o corpo da mulher passa por diversas alterações imunológicas, metabólicas, endócrinas e vasculares ${ }^{3}$. Essas alterações ocorrem para manter o sistema imunológico materno tolerante aos antígenos paternos de histocompatibilidade maior expressos pelo feto, tornando, assim, a gestação uma estimulação do sistema imunológico. Em geral, as mulheres grávidas são grupo de risco para qualquer infecção, porque têm imunidade mais baixa. Nesse sentido, é essencial investir na orientação das mulheres sobre a importância da vacinação, o que implica na necessidade de um seguimento mais próximo, com supervisão e reforço, fundamentais na assistência pré e pós-natal ${ }^{4}$.

De acordo com os dados obtidos no Sistema de Informação do Programa Nacional de Imunização (SI-PNI), o grupo que menos aderiu a essa campanha foi o das gestantes, apresentando uma cobertura de 77,1\%. Em Minas Gerais, o percentual de grávidas que vacinaram foi apenas de $64,4 \%$. Na cidade de Engenheiro Navarro, situada ao norte do estado, a cobertura foi ainda menor, $52,3 \%{ }^{5}$. Apesar das explicações com relação à campanha de vacinação contra a Influenza A (H1N1), houve muitos comentários e boatos sobre a real veracidade e eficácia da vacina, o que contribuiu, em muito, para uma não aceitação da campanha ${ }^{2}$. Considerando a importância das campanhas de vacinação como forma de prevenção mais eficaz na diminuição dos casos do vírus da Influenza no geral, este estudo teve por objetivo compreender os motivos que levaram as gestantes a não se vacinarem contra a Influenza A (H1N1).

\section{Metodologia}

Trata-se de um estudo de caráter descritivo, com abordagem qualitativa, com opção pelo uso do referencial teórico-metodológico da Teoria das Representações Sociais (TRS). A TRS é um instrumental diferenciado, com aplicação em trabalho de pesquisa, com especial interesse na área de saúde, ao buscar junto a grupos, setores e segmentos da população aprender sua experiência, voz e saberes não instituídos como conhecimento acadêmico, mas dentro de um contexto social determinado ${ }^{6}$. Em relação à pesquisa qualitativa, Minayo $^{7}$ a descreve como aquela que não é baseada no critério numérico a fim de garantir sua representatividade, mas privilegia os sujeitos sociais que detêm os atributos que o pesquisador deseja conhecer.

O estudo foi realizado na área de abrangência de uma equipe da Estratégia Saúde da Família (ESF) da cidade de Engenheiro Navarro, Minas Gerais, situada ao norte do estado. O município conta atualmente com duas equipes de ESF que atendem a cidade e toda a sua comunidade rural.

Participaram do estudo 10 mulheres que estavam grávidas no período da campanha de vacinação de 2010 e que se encontravam cadastradas na ESF. As mulheres foram selecionadas por meio de levantamento realizado pelo enfermeiro e por agentes comunitários de saúde. O número de entrevistadas foi definido a partir da saturação de dados, ou seja, quando nenhuma informação nova era referida pelos participantes. As entrevistas aconteceram no mês de maio de 2011, na residência das entrevistadas e tiveram a duração aproximada de 15 a 40 minutos. 
Os dados foram obtidos por meio de uma entrevista semiestruturada, estabelecida mediante um roteiro. A questão norteadora que direcionou a entrevista foi: "Quais motivos levaram a senhora a não tomar a vacina da gripe suína, quando estava grávida?". As entrevistas foram previamente agendadas, definindo-se local e horário mais convenientes para as mulheres para a aplicação do instrumento de coleta de dados. As entrevistas foram realizadas mediante assinatura do Termo de Consentimento Livre e Esclarecido. Para garantir o anonimato, as mulheres que se encontravam gestantes no período da vacinação foram identificadas como G1, G2, sucessivamente.

A presente pesquisa foi autorizada pelo Comitê de Ética em Pesquisa das Faculdades Unidas do Norte de Minas (Funorte).

As informações obtidas foram gravadas e, posteriormente, transcritas na íntegra. Em segui$\mathrm{da}$, os dados coletados foram analisados em categorias. Procedeu-se utilizando a análise temática de conteúdo de acordo com $\mathrm{Minayo}^{7}$. A análise foi realizada em três fases: pré-análise, exploração do material e tratamento dos resultados. Após a transcrição das entrevistas, foram realizadas leituras repetidas e exaustivas do material colhido, permitindo ordenar o conjunto dos dados obti$\operatorname{dos}^{7}$. Iniciou-se, assim, uma primeira classificação para apreender as estruturas relevantes; possibilitando o desvelamento das categorias empíricas confrontadas à luz da literatura atual.

\section{Resultados}

\section{Categorias emergentes}

A partir da análise dos depoimentos das entrevistadas, foi possível identificar as categorias emergentes, sendo: "Motivos para a não vacinação", "A importância da vacina", "Orientação no Pré-natal" e "A Divulgação da mídia”. Em seguida, foi realizado um paralelo entre os discursos do sujeito, a literatura e o olhar dos pesquisadores.

\section{Motivos para a não vacinação}

Essa categoria contempla os discursos das entrevistadas que estão relacionados com os motivos que levaram as mulheres a não se vacinarem.

Foram constatados comentários em torno da nova doença e sobre a veracidade e eficácia da vacina. Esse fato acabou por ocasionar uma contrariedade da população em torno da vacinação.

Porque tiveram muitos boatos que a vacina provocava algumas reações. (G7)
Foram os comentários, a falta de conhecimento e por isso fiquei com medo de tomar e prejudicar o bebê e a minha saúde. (G8)

Conforme observado em relato abaixo, emergiu, entre as entrevistadas, o fato de os cuidados serem cada vez maiores na gravidez, uma vez que é um momento muito esperado e diferenciado na vida da mulher.

Pelo fato de eu te perdido um bebê há dois meses, o medo dessa gravidez, por ser uma gravidez tão esperada, então eu fiquei com medo de perder novamente. (G4)

Pode-se constatar nas falas que muitos mitos e crenças envolveram a vacina $\mathrm{H} 1 \mathrm{~N} 1$, e todas essas reações estavam vinculadas a informações que vinham sendo criadas pela própria população.

É! Bom ... na época eu andei lendo algumas matérias sobre o assunto, onde muitas que eu li falava que a vacina por conter uma quantidade alta de mercúrio nessa época, poderia causar risco ao bebê. Senti muitas dúvidas na época, havia rumores que a vacina continha conservantes que poderiam causar risco ao bebê. (G6)

Tinha medo do bebê nascer aleijado, com má formação. (G9)

A vacina era de alto risco para o bebê, pois poderia nascer com alguma sequela, ou vir a acarretar um aborto. (G8)

As mulheres relataram dúvidas acerca dos benefícios, eventos adversos e reações que a vacina poderia ocasionar.

Qual benefício da vacina, as reações que ela poderia causar; se não poderia prejudicar o bebê, causando um aborto ou vindo acarretar uma má formação do feto? É por isso, eu não quis arriscar. (G8)

Senti muita dúvida sim. Eu queria ter tomado para eu prevenir e não tomei justamente por falta de informação e medo. (G1)

Senti muitas dúvidas, na época, havia rumores que a vacina contém conservantes que poderiam causar risco ao bebê. (G6)

Percebe-se também que as mulheres não procuraram compreender a vacina, seus efeitos e as contribuições para o binômio mãe-filho.

$V i$ por minha parte um certo assim descaso, digamos dessa forma, a saber ter informações assim mais claras. Eu não sei se é porque a mídia também não procurou informar direito, com isso houve certo desinteresse. Eu não me senti tocada em saber assim mais a respeito da mesma. (G5)

Observou-se, entre as entrevistas, certo receio em se vacinar; isso devido aos comentários relacionados aos possíveis eventos adversos que a vacina Influenza A (H1N1) estaria causando.

Por alto me falaram coisas ruins, que doía muito e inchava o braço e que corria vários riscos. (G3) 
Vômito, febre, dor no corpo; aí fiquei com medo porque já tinha muito enjoo causado pela gravidez. (G7)

\section{A importância da vacina}

As mulheres também tiveram representação positivas sobre a vacina. Identificou-se que a vacina tem a representação de "protetora para a mãe e para o feto"; um elemento que "evita parto prematuro" e que "previne a morte".

Porque é uma doença muito perigosa que a gente ainda não tem tanto conhecimento. Então a vacina já evita e previne bastante. (G1)

Porque é importante para imunizar a gente, porque essa gripe está levando muita gente a morte, então acho muito importante. (G4)

Há, eu acho, e hoje para mim está mais claro, pois a vacina imuniza tanto a mãe quanto ao bebê evitando parto prematuro não coloca em risco as mães, pois elas ficam a imunidade baixa e mais fácil de contaminar. (G6)

No depoimento abaixo, é constatada a maior aceitabilidade com relação à vacina a partir do esclarecimento do benefício de se imunizar o contra $\mathrm{H} 1 \mathrm{~N} 1$.

Atualmente foram esclarecidas todas as duvidas que eu tinha naquela época. Hoje eu tenho outro conhecimento sobre a vacina que não tinha na época dessa vacinação. (G8)

Percebem-se que os conceitos que a população possuía acerca da vacina Influenza A (H1N1) se modificaram desde sua campanha em 2009/ 2010. Muitos questionamentos e dúvidas da população foram esclarecidos possibilitando a geração de um novo conceito acerca da vacina.

\section{Orientação no pré-natal}

Foi possível perceber, nos depoimentos, a possibilidade de intercâmbio de experiências e conhecimentos entre o profissional de saúde e o paciente, conforme evidenciado abaixo:

A médica me orientou, mas fiquei com medo de prejudicar o meu bebê, com um aborto ou nascer com sequela. Aí resolvi não tomar. (G10)

Olha, no período da gestação eu fiz um prénatal particular e então a médica, ela pediu que eu tomasse algumas vacinas, e a H1N1 era uma delas. Aí eu procurei, mas não teve condições de tomar a vacina porque não havia nos postos de saúde. Ela explicou que eu havia de tomar a vacina que é importante assim de eu me precaver das possíveis infecções. Então foi de uma forma superficial. (G5)

Foi observada ainda a falta de orientação acerca da vacina contra a Influenza A H1N1 durante o pré-natal, como apontado a seguir pela entrevistada G7.

Eu não recebi orientação porque meu pré-natal foi feito por médicos diferentes e nenhum deles me orientou quanto à importância da vacina. Porque era uma doença de alto risco para gestante e tendo a orientação de um profissional interado do assunto poderia ter esclarecido dúvidas quanto à vacina. (G7)

Contudo, é destacada, na fala abaixo, a maior aceitabilidade com relação à vacina a partir do esclarecimento do benefício de se imunizar contra o H1N1.

Atualmente foram esclarecidas todas as dúvidas que eu tinha naquela época. Hoje eu tenho outro conhecimento sobre a vacina que não tinha na época dessa vacinação. (G8)

\section{A divulgação da mídia}

Quando perguntadas como obtiveram a informação sobre a campanha de vacinação, observou-se que as respostas das entrevistadas estavam vinculadas à televisão, aos jornais e à internet.

Pela televisão, as campanhas nos jornais, programas, televisão, rádio. (G1)

Por via televisiva mesmo, é então dessa forma que eu fiquei sabendo. (G5)

\section{Discussão}

Os depoimentos das gestantes apontaram para aspectos relacionados à pergunta norteadora do estudo. Nos relatos, é possível observar o destaque dado aos motivos que levaram as gestantes a não se vacinarem contra a Influenza A (H1N1). Foram várias as questões envolvidas nas respostas quanto ao motivo que as levaram a não se imunizarem contra a Influenza A (H1N1). É importante ressaltar que esses motivos estão associados ao medo, à falta de informação e aos mitos e crenças que a população traz nas suas representações e nos seus valores culturais.

Evidenciou-se um potencial elevado de relatos alusivos ao sentimento de medo no início do período pandêmico em 2009. É compreensível esse sentimento, visto que a pandemia, em seu auge, era alimentada por novas informações que, quando repassadas pela população leiga, tomavam proporções maiores do que os dados oficiais. Em outras palavras, pode-se observar que as pessoas apresentam certo receio em aceitar tudo que é novo e, se elas não recebem as orientações corretas, não aderem, mesmo que isso possa colocar em risco sua saúde ${ }^{2}$. 
Foi possível perceber que algumas mães passaram por situações difíceis em gestações anteriores, o que acabou por provocar certo medo, já que houve comentários negativos com relação à nova vacina que começava a ser aplicada na população de gestantes. O receio de um possível aborto foi expresso pela mãe em decorrência de receber a vacina contra o H1N1. As mulheres que vivenciaram a perda de um filho, que estava sendo gerado, merecem cuidados da equipe de saúde, em especial, da enfermagem. Muitas não esperam esse acontecimento, sentindo-se desanimadas, frustradas, tristes, fragilizadas, culpadas, podendo evoluir para a depressão ${ }^{8}$.

Os indivíduos reconstroem metaforicamente a doença, relacionando-a tanto com suas experiências pessoais quanto com sua bagagem cultural, suas tradições e seus mitos. É importante ressaltar que estes fazem parte das interpretações que cada sociedade tem sobre sua realidade ${ }^{9}$. A elaboração mítica tem por objetivo justificar, racionalizar e legitimar realidades socioculturais. O mito representa um modelo de ação com o qual o grupo dominante estabelece os conteúdos simbólicos e de dominação para garantir seus interesses ${ }^{10}$.

A população traz, junto aos anos vividos, uma bagagem de culturas e crenças que respeita bem mais do que a própria ciência, pois suas crenças vêm de muitos anos com seus antepassados e a ciência, para ela, ainda é muito nova. Mesmo que a ciência se proponha a explicar todos os fenômenos por meio de métodos científicos, evidencia-se que, na população, ainda permeiam crenças diversas relacionadas à saúde. Os sentidos sociais produzidos em torno da doença se tornam símbolos que determinam específicas dinâmicas sociais, pois é nas relações entre os indivíduos que estes se definem e se confirmam constantemente. Nas relações sociais, estes símbolos tornam-se legítimos, agem e manifestam-se. Os mitos e as crenças populares, os medos, a experiência social sobre o fenômeno da doença são fatores que acionam os mecanismos humanos".

A prevenção de doenças por meio de campanhas necessita de uma conscientização e mobilização da população para que o resultado almejado seja alcançado. A comunicação social tem o papel primordial de persuadir e conscientizar, por meio da informação. A análise das estratégias e instrumentos utilizados em seduzir a sociedade para ações de saúde pública, bem como o alcance das informações divulgadas, permite-nos distinguir a eficiência das campanhas de vacinação ${ }^{11}$.

A comunicação social merece destaque na saúde pública, como nas campanhas de vacina- ção. A esta foi conferida a incumbência, a responsabilidade de proporcionar o alcance das metas traçadas pelo Ministério da Saúde, por meio da disseminação da informação, visando conscientizar e mobilizar a população sobre a importância da vacina no processo de prevenção e erradicação da doença, como aconteceu no caso da poliomielite ${ }^{11}$.

Pelos relatos, nota-se que houve falta de acesso às fontes de comunicação aos serviços e profissionais de saúde, ou seja, a falta de contato com a ESF, com o enfermeiro e o médico, que estavam ligados diretamente com as gestantes durante a realização do pré-natal.

O valor da informação está localizado em uma realidade específica e potencializado na transferência. Este valor é relativo e específico para cada indivíduo e depende da preferência por uma informação em detrimento de outra e da competência cognitiva para compreender as informações e estabelecer possível comparação ${ }^{11}$. Contudo, foi possível perceber, nos relatos, que as mulheres não procuraram compreender a vacina, seus efeitos e as contribuições que esta poderia propiciar para si e seu filho.

No estudo, foi constatada a questão dos eventos adversos como justificativa para a não vacinação das mulheres nas campanhas de imunização contra a H1N1. A preocupação com a ocorrência de eventos adversos tem sido apontada como um fator que contribui para as baixas coberturas vacinais. Muitas vezes, atribui-se à imunização sintomas nem sempre associados verdadeiramente à vacina. Estudos sobre a percepção e representação dos sintomas após a vacinação podem esclarecer parte dos motivos de baixas coberturas vacinais e contribuir para intervenções educativas mais específicas ${ }^{12}$.

Em relação aos eventos adversos pós-vacinais (EAPV), é preciso que os relatos sejam apreciados numa perspectiva adequada, como instrumento de busca de qualidade dos programas de imunização. Nenhuma vacina está livre totalmente de provocar eventos adversos, porém os riscos de complicações graves causados pelas vacinas do calendário de imunizações são muito menores do que os das doenças contra as quais elas protegem ${ }^{2}$. Observou-se, entre as entrevistadas, certo receio em se vacinar devido aos comentários relacionados aos possíveis eventos adversos que a vacina contra a Influenza $\mathrm{A}$ (H1N1) estaria causando.

Os EAPV da Influenza A (H1N1) mais detectados consistem em reações locais como vermelhidão e/ou dor no local de aplicação da vacina, 
problemas que geralmente desaparecem espontaneamente em pouco tempo. Também é realçada, embora com menor frequência, a ocorrência de febre, cefaleia, cansaço e dores musculares; sintomas gastrointestinais: náuseas e vômitos. Entretanto, sabe-se que muitos desses eventos consistem em associações temporais em que a vacina muitas vezes não é a responsável ${ }^{1}$.

A gravidez é um período de várias mudanças físicas e emocionais, que cada mulher vivencia de forma distinta. Essas mudanças podem gerar medos, dúvidas, angústias e fantasias. Informações sobre as diferentes vivências devem ser trocadas entre as mulheres e os profissionais de saúde. Nos discursos, foi constatada a possibilidade de intercâmbio de experiências e conhecimentos, considerada a melhor forma de promover a compreensão do processo de gestação ${ }^{13}$. Isto mostra a importância da orientação à gestante no momento da vacinação, pois constitui um dos elementos essenciais para a continuidade e o sucesso dos programas de imunização, permitindo que adquiram o conhecimento e pratiquem atitudes adequadas a todo o processo.

A fragmentação nas ações de saúde foi observada em um dos relatos das entrevistadas, fato esse resultante da inexistência da continuidade dos cuidados. Dessa forma, verificou-se ainda o não cumprimento do princípio de longitudinalidade na assistência à saúde da gestante. Para a consumação do cuidado, é indispensável a comunicação como ferramenta necessária à assistência à saúde, com vistas ao estabelecimento de confiança e a vinculação do usuário ao profissional e, consequentemente, ao serviço de saúde. Com o acompanhamento contínuo do pré-natal pelo mesmo profissional, são estabelecidas relações de confiança e segurança $\mathrm{a}^{14,15}$.

Para tratar de saúde e alcançar êxito, é preciso contar com o amplo apoio da opinião pública. Isso só será possível com a participação ativa e criativa de todos como verdadeiros agentes de promoção da saúde. Para isso, é necessário também o empenho dos profissionais da saúde em serem, por natureza, comunicadores e educadores em suas atividades cotidianas. Em um dos relatos, foi constatada a maior aceitabilidade com relação à vacina a partir do esclarecimento do benefício de se imunizar contra a H1N1.

No período compreendido entre 2009 e 2010, observaram-se mudanças nas representações que a população possuía sobre a vacina Influenza A (H1N1). Este fato pode ser devido ao esclarecimento das questões e dúvidas da população, possibilitando a geração de um novo conceito acerca da vacina. A vacina passou a ser representada como "protetora para a mãe e para o feto"; um elemento que "evita parto prematuro" e que "previne a morte".

Foi observado, em poucos meses, que as pessoas parecem ter substituído o medo pela gripe A pelo medo da vacina contra tal doença e, ao deixarem de se imunizar, a população parece ter se esquecido do pânico vivido há menos de um ano. Assim como aconteceu com a gripe Espanhola, bastou o vírus recuar para a população avaliar a ameaça do novo vírus como um passado distante ${ }^{2}$.

Outra questão destacada no estudo diz respeito às fontes de informação obtidas pela população acerca da nova vacina disponibilizada pelo Ministério da Saúde contra a Influenza A (H1N1). As principais fontes apontadas pelas entrevistadas foram a televisão, o rádio e a internet. Os meios de comunicação representam um dos principais elos para a compreensão da dinâmica entre comportamento humano, contexto social e políticas públicas. A imprensa também contribui para a formação de conceitos, atitudes e expectativas sociais que podem favorecer um clima de aceitação, ou rejeição, de questões críticas. Além disso, a mídia é um amplo meio de divulgação (televisão, radio e internet), tornando-se assim, um veículo de comunicação de fácil acesso para a população. Ela representa um grande aliado junto à aceitação das pessoas em torno de determinado assunto, pois faz com que sua linha de pensamento se torne a da população ${ }^{16}$.

A forma como a epidemiologia dos fatores de risco aparece nos meios de comunicação é um tema relevante para a saúde pública. $\mathrm{O}$ modo da medicina estar presente na mídia traz, então, dois problemas adicionais para a saúde pública, tão relevantes quanto a distância entre o consenso médico e o que aparece na mídia. Primeiro, realçar o que está ao alcance da ação dos indivíduos simplifica a causalidade dos problemas, reduzindo a capacidade de lidar com eles. Em segundo lugar, ao colocarem o advento de uma doença como consequência da opção, as notícias sobre fatores de risco parecem ser regras morais, pois identificam sofrimento a castigo ${ }^{17}$.

\section{Considerações finais}

Neste estudo, foram destacados aspectos referentes aos motivos de não vacinação das gestantes de Engenheiro Navarro, Minas Gerais, o que restringe sua validade aos dados empíricos nos 
quais se apoiaram. É pertinente e enriquecedor do ponto de vista prático e teórico a realização de novos estudos que possam vir a complementar ou alargar as bases aqui construídas. Como existem poucos estudos nacionais e internacionais sobre o tema é desejável que novas pesquisas sejam desenvolvidas no sentido de propiciar ampla discussão, visando o conhecimento dos profissionais envolvidos na assistência às gestantes $\mathrm{e}$ promovendo a melhoria da assistência.

Por fim, é imprescindível que as gestantes recebam as orientações corretas acerca da vacina contra a Influenza A (H1N1) durante o pré-natal, no sentido de disseminar tais informações entre essa população. Na primeira campanha, as gestantes possuíam representações negativas em torno da vacina $\mathrm{H} 1 \mathrm{~N} 1$, tendo-a como "causadora de aborto" e de "alto risco para o bebê". À medida que as dúvidas sobre a vacina foram esclarecidas, as representações se modificaram, tornando-se positivas como "protetora para a mãe e para o feto" e como um elemento que "evita parto prematuro". Assim, torna-se essencial o desenvolvimento de estratégias de comunicação entre o profissional de saúde e as gestantes para o estabelecimento de relação de confiança e estudos das representações acerca das campanhas de vacinação, em especial, envolvendo a Influenza A (H1N1).

\section{Colaboradores}

BFB Pereira e MAS Martins participaram da coleta e da redação do artigo; TL Andrade-Barbosa, LM Xavier-Gomes e CSO Silva participaram da redação e da análise do artigo. 


\section{Referências}

1. Machado AA. Infecção pelo vírus Influenza A (H1N1) de origem suína: como reconhecer, diagnosticar e tratar. J Bras Pneumol 2009; 35(5):464-469.

2. Brasil. Ministério da Saúde (MS). Protocolo de Vigilância Epidemiológica de Eventos Adversos PósVacinação. Estratégia de Vacinação contra o Vírus Influenza Pandêmico (H1N1). Brasília-DF: MS; 2010.

3. Celestino N, Delgado JL, Medina JL. Alterações Endócrinas e Imuno-modulação na Gestação. Serviço de Endocrinologia, Unidade de Investigação e Desenvolvimento Cardiovascular. Arqui Med 2007; 21(5):175-182.

4. Narchi NZ. Atenção pré-natal por enfermeiros na Zona Leste da cidade de São Paulo, Brasil. Rev esc enferm USP 2010; 44(2):266-273.

5. Brasil. Ministério da Saúde (MS). Sistema de Informação do Programa Nacional de Imunização (SIPNI). Estratégia de vacinação contra influenza pandêmica. [acessado 2011 abr 30]. Disponível em: http:/ /pni.datasus.gov.br/consulta_h1n1_10_selecao.asp enviar $=0 k \& s e l=$ vacinometro\&faixa $=$ todos\&grupo $=$ todos\&uf=TO\&municipio $=171620$.

6. Pugliesi MV, Tura LFR, Andreazzi MFS. Mães vacinação das crianças: representações sociais em serviço público de saúde. Rev Bras Saude Mater Infant 2010; 10(1):75-84.

7. Minayo MCS. O desafio do conhecimento: pesquisa qualitativa em saúde. 10a Edição. São Paulo: Hucitec-Abrasco; 2007.

8. Bazotti KDV, Stumm EMF, Kirchner RM. Ser cuidada por profissionais da saúde: percepções e sentimentos de mulheres que sofreram abortamento. Texto contexto - enferm 2009; 18(1):147-154.

9. Magnani C, Oliveira BG, Gontijo EDG. Representações, mitos e comportamentos do paciente submetido ao implante de marcapasso na doença de Chagas. Cad Saude Publica 2007; 23(7):1624-1632.
10. Silva AX, Cruz EA, Melo V. A importância estratégica da informação em saúde para o exercício do controle social. Cien Saude Colet 2007; 12(3):683-688.

11. Cunha SS, Camacho LAB, Santos AC, Dourado I. Imunização contra Influenza no Brasil: racionalidade e desafios. Rev Saude Publica 2005; 39(1):129-136.

12. Santos BLR, Creutzberg M, Cardoso RFML, Lima SF, Gustavo AS, Viegas K, Welfer M, Souza ACA. Situação vacinal e associação com a qualidade de vida, a funcionalidade e a motivação para o autocuidado em idosos. Rev bras epidemiol 2009; 12(4): 533-540.

13. Brasil. Ministério da Saúde (MS). Manual Técnico: pré-natal e puerpério. Brasília/DF: MS; 2003.

14. Barbosa TLA, Xavier-Gomes LM, Dias OV. O prénatal realizado pelo enfermeiro: a satisfação das gestantes. Cogitare Enferm 2011; 16(1):29-35.

15. Souza MHN, Tyrrell MAR. Políticas de salud a la mujer em Brasil, 1974-2004. Rev enferm UERJ 2011; 19(1):70-76.

16. Lacerda AE, Mastroianni FC, Noto AR. Tabaco na mídia: análise de matérias jornalísticas no ano de 2006. Cien Saude Colet 2010; 15(3):725-731.

17. Vaz P. Mídia, moralidade e fatores de risco em saúde. Cad Saude Publica 2009; 25(3): 472-73.

Artigo apresentado em 02/08/2011

Aprovado em 25/08/2011

Versão final apresentada em 02/09/2011 